\title{
PROFIL, ALOKASI DAN PENDAPATAN TENAGA KERJA PADA PERKEBUNAN KELAPA SAWIT RAKYAT DI KABUPATEN SOLOK SELATAN
}

\section{PROFIL, ALLOCATION, AND LABOR INCOME ON PALM OIL SMALLHOLDERS SOLOK SELATAN DISTRICT}

\author{
Yulistriani dan Mahdi \\ Faculty of Agriculture Andalas University \\ email: yani_ni87@yahoo.com
}

\begin{abstract}
Labor is one of the main inputs in the production activities, including in agriculture. The quality and quantity of labor would have an impact on quality of products. Solok Selatan district is a new district in West Sumatera that has priority program for development of palm oil smallholders. The quality of labor will also determine the sustainability and success of the operational of palm oil smallholders. Field surveys and in-depth interviews had been carried out to find the profile, allocation and labor income of palm oil smallholders in Solok Selatan district. Respondents for this research were selected purposively with the criteria of land ownership is $\geq 2$ hectares. This is because the farmers who have land area $\geq 2 \mathrm{Ha}$ tend to use labor from outside the family and otherwise. The research finds that labors of palm oil smallholder in the research site were dominated by workers with primary education level (75\%). Moreover, the average of work time allocation by respondents is was $84.5 \mathrm{HOK} / \mathrm{ha} / \mathrm{year}$. Meanwhile, the average income per month of the labors were Rp. 1,393,916.67 (flat land) and Rp. 1,786,083.33 $1,837,333,33$ (steep land) with assumption that each type of work available at any time and labors actively work for 8 hours per day in oil palm smallholder.
\end{abstract}

Keywords: Profil, Allocation, Income, labour, palm oil

\section{PENDAHULUAN}

Pembangunanperkebunankelapasawitmempunyaidampakgandaterhada pekonomi wilayah, terutama dalam menciptakan kesempatan dan peluang kerja. Pembangunan perkebunan kelapa sawit memberikan tetesan manfaat (trickle effect), sehingga dapat memperluas daya penyebaran (power of dispersion) pada masyarakat sekitarnya. Semakin berkembangnya perkebunan kelapa sawit, semakin terasa dampaknya terhadap tenaga kerja yang bekerja pada sektor perkebunan dan sektor turunannya. Dampak tersebut dapat dilihat dari peningkatan pendapatan masyarakat petani, sehingga meningkatnya daya beli masyarakat pedesaan, baik untuk kebutuhan primer maupun kebutuhan sekunder (Syahza, 2011). 
Pembangunan subsektor kelapa sawit merupakan penyedia lapangan kerja yang cukup besar dan sebagai sumber pendapatan petani. Kelapa sawit merupakan salah satu komoditas yang memiliki andil besar dalam menghasilkan pendapatan asli daerah, produk domestik bruto, dan kesejahteraan masyarakat (Afifuddin, 2007). Menurut Taryono (2012) pemerintah daerah diharapkan mampu meningkatkan pendapatan asli daerah melalui pengembangan aktivitas ekonomi berbasis komoditi unggulan daerah.

Pemerintah Kab. Solok Selatan bersama masyarakat mempunyai visi yang sama dalam membangun kemandirian dan pertumbuhan ekonomi melalui kebijakan pembangunan yang menitikberatkan pada pengembangan komoditi unggulan daerah baik bidang pertanian, perkebunan, peternakan dan perikanan yang berwawasan agribisnis. Data statistik menunjukkan bahwa salah satu komoditi unggulan sektor perkebunan di Kabupaten Solok Selatan adalah komoditi kelapa sawit dengan produksi yang terus meningkat dari tahun ke tahun (BPS, 2013).

Masalah yang sering dihadapi petani dalam pengelolaan usaha perkebunan kelapa sawit adalah kurangnya pengetahuan dalam hal teknis budidaya, perawatan tanaman serta penggunaan jumlah sarana produksi yang tepat dan optimal. Menurut Suryana et al. (1982), keberhasilan suatu usahatani tidak hanya ditentukan oleh kehandalan teknologi yang diterapkan dan dukungan sumberdaya alam, tetapi juga oleh karakteristik individu petani dan tenaga kerja yang terlibat di dalam proses pengelolaan usaha perkebunan kelapa sawit. Kualitas dan ketersediaan tenaga kerja menentukan arah pertumbuhan sektor perkebunan khususnya pada tanaman kelapa sawit. Oleh karena itu pembahasan mengenai alokasi tenaga kerja dan pendapatan kebun rakyat kelapa sawit penting untuk dibahas secara mendalam sehingga ditemukan proporsi yang seimbang antara alokasi tenaga kerja dan pendapatan pada kebun rakyat kelapa sawit.

\section{METODE PENELITIAN}

Metode penelitian ini adalah deskriptif kualitatif. Menurut Nazir (2005), metode deskriptif adalah pencarian fakta dengan interpretasi yang tepat. Tujuan dari penelitian deskriptif ini adalah untuk membuat deskripsi, gambaran atau lukisan secara sistematis, faktual dan akurat mengenai fakta-fakta, sifat-sifat serta hubungan antar fenomena yang diselidiki. Penelitian kualitatif pada dasarnya merupakan suatu proses penyidikan, mirip pekerjaan detektif yang secara meyakinkan dikemukakan oleh Douglas (1976) dalam lisa (2010).

Penelitian dilakukan di Kec. Sangir Balai Janggo Kab. Solok Selatan pada bulan Juli-Agustus 2016. Penentuan lokasi penelitian dilakukan secara purposive (sengaja). Data statistik (Solok Selatan Dalam Angka, 2015) menunjukkan bahwa Kecamatan Sangir Balai Janggo mempunyai jumlah produksi tertinggi untuk komoditi Kelapa Sawit di Kabupaten Solok Selatan dengan luas lahan sebesar 
639 Ha dan jumlah petani 417 orang.Populasi dari penelitian ini adalah petani kelapa sawit di Kabupaten Solok Selatan yang mengelola kebunnya dengan pola kebun rakyat. Sampel diambil secara acak sederhana (simple random sampling) sebanyak 30 orang dengan kriteria luas lahan $\geq 2$ Ha dan tanaman telah menghasilkan (umur tanaman diatas 3 tahun). Hal ini dilakukan karena dari survey dilapangan didapatkan informasi bahwa petani dengan luas lahan $<2$ Ha hanya memanfaatkan tenaga kerja dalam keluarga, sedangkan petani dengan luas lahan $\geq 2$ Ha menggunakan tenaga kerja luar keluarga untuk membantu pelaksanaan usahatani mereka.

\section{HASIL DAN PEMBAHASAN}

\section{Gambaran Umum Lokasi Penelitian}

Kabupaten Solok Selatan berada pada jajaran Pegunungan Bukit Barisan yang termasuk dalam daerah Patahan Semangka. Posisi daerah secara geografis berada pada $01^{\circ} 17^{\prime} 13^{\prime \prime}-01^{\circ} 46^{\prime} 45^{\prime \prime}$ Lintang Selatan dan $100^{\circ} 53^{\prime} 24^{\prime \prime}-101^{\circ} 26^{\prime}$ $27^{\prime \prime}$ Bujur Timur. Dengan luas wilayah lebih kurang $3.590 \mathrm{Km}^{2}$. Tepatnya berada di bagian selatan Provinsi Sumatera Barat. Ibu kota Kabupaten Solok Selatan sendiri ditetapkan berkedudukan di Padang Aro. Jarak antara Padang Aro dengan Kota Padang adalah $166 \mathrm{Km}$. Secara administratif, sejak tahun 2011 Kabupaten Solok Selatan terdiri dari tujuh kecamatan, yaitu (i) Sangir, (ii) Sangir Jujuan, (iii) Sangir Balai Janggo, (iv) Sangir Batang Hari, (vi) Sungai Pagu, (vi) Pauh Duo dan (vii) Koto Parik Gadang Diateh. Secara keseluruhan kabupaten ini terdiri dari 39 nagari dan 220 jorong. Tiap kecamatan ini memiliki luas yang bervariasi. Kecamatan terluas adalah Kecamatan Sangir Balai Janggo dengan luas 686,94 $\mathrm{km}^{2}$ atau sekitar 20,53\% dari luas keseluruhan Kabupaten Solok Selatan dan Kecamatan Sangir dengan luas 632,99 km².

Penggunaan lahan di wilayah Kabupaten Solok Selatan didominasi oleh penggunaan untuk kawasan hutan yang mencapai luas 261.000 Ha atau sekitar 72,70 \% dari total luas wilayah Kabupaten Solok Selatan 359.000 Ha. Selanjutnya kegiatan perkebunan merupakan penggunaan lahan terbesar kedua yang mempunyai luas 79.800 Ha atau sekitar $22,23 \%$.

\section{Profil Tenaga Kerja}

Perkebunan kelapa sawit rakyat mempunyai spesifikasi tersendiri dalam penggunaan tenaga kerja disetiap tahapan pengelolaan lahan kelapa sawit. Menurut undang-undang no.13 tahun 2003 Perencanaan tenaga kerja adalah proses penyusunan rencana ketenagakerjaan secara sistematis yang dijadikan dasar dan acuan dalam penyusunan kebijakan, strategi, dan pelaksanaan program pembangunan ketenagakerjaan yang berkesinambungan. Perencanaan tenaga kerja disusun atas dasar informasi ketenagakerjaan yang antara lain 
meliputi: penduduk dan tenaga kerja, kesempatan kerja, pelatihan kerja termasuk kompetensi kerja, produktivitas tenaga kerja, hubungan industrial, kondisi lingkungan kerja, pengupahan dan kesejahteraan tenaga kerja, dan jaminan sosial tenagakerja.

Di dalam dokumen Rencana Strategis Direktorat Jenderal Perkebunan 2010-2014 disampaikan bahwa salah satu startegi pembangunan sektor perkebunan adalah dengan mengembangkan sumber daya manusia. Sumberdaya manusia dalam bidang perkebunan diarahkan untuk mendukung berlangsung nyaproses perubahan guna terwujudnya sistem dan usaha agribisnis perkebunan yang bertumpu kepada kemampuan dan kemandirian pelaku usaha perkebunan. Sektor pertanian menunjukan trend aging agriculture, yaitu suatu kondisi dimana tenaga kerja yang berada di pertanian adalah tenaga kerja yang berusia lanjut. Tenaga kerja pertanian sampai saat ini masih didominasi oleh tenaga kerja dengan tingkat pendidikan SD ke bawah, yang jumlahnya mencapai 81 persen dari tenaga kerja pertanian.

Dari penelitian yang dilakukan pada kebun rakyat komodiit kelapa sawit di Kab. Solok Sleatan ditemukan bahwa $\pm 75 \%$ tenaga kerja yang bekerja pada perkebunan rakyat komoditi kelapa sawit adalah tenaga kerja tingkat pendidikan SD ke bawah, 25\% lainnya diisi oleh tenaga kerja berpendidikan SMA dan SMP. Namun trend aging agriculture (tenaga kerja usia lanjut, 60 tahun ke atas)hanya sebesar $\pm 38 \%, 62 \%$ lainnya diisi oleh tenaga kerja yang relatif muda dengan usia 28 s.d 40 tahun. Tenaga kerja pada perkebunan rakyat komoditi kelapa sawit di Kab. Solok Selatan, khususnya di Kec. Sangir Balai Janggo sekitar tahun 2004 s.d 2011 didominasi oleh tenaga kerja yang berasal dari suku Jawa, namun terjadi pergeseran sekitar tahun 2012 sampai saat ini (2016), penduduk asli Kab. Solok Selatan sudah mulai mengisi pekerjaan sebagai tenaga kerja pada perkebunana rakyat komoditi kelapa sawit.

Disetiap tahapan pekerjaan dalam pengelolaan perkebunan rakyat komoditi kelapa sawit memerlukan keterampilan khusus dan keuletan. Dari wawancara dilapangan, pemilik lahan juga mempunyai pertimbangan khusus dalam pemilihan tenaga kerja yaitu nilai-nilai kejujuran. Hal ini menjadi pertimbangan penting bagi pemilik lahan karena sebagian besar pemilik lahan menyerahkan sepenuhnya kepada pekerja. Pemilik hanya melakukan pengawasan ke area perkebunan mereka sewaktu-waktu jika dibutuhkan. Untuk penjualan hasil produksipun tenaga kerja yang langsung berkoordinasi dengan toke yang membeli hasil produksi mereka.

\section{Alokasi Tenaga Kerja}

Tenaga kerja merupakan faktor produksi yang penting dan perlu diperhitungkan dalam proses produksi. Tenaga kerja lebih penting dari faktor produksi lain seperti bibit, tanah dan air, sebab manusialah yang menggerakkan faktor-faktor tersebut untuk menghasilkan sesuatu jenis barang (Bukit dan Bakir, 
1998 dalam Alfayanti dan Zul, 2013). Selanjutnya Alfayanti dan Zul (2013) juga menyatakan bahwa curahan tenaga kerja yang diberdayakan oleh petani dalam usahatani kelapa sawit rakyat rata-rata berjumlah 85,79 HOK/tahun. Tenaga kerja ini diberdayakan pada kegiatan pemupukan, penyiangan, penyemprotan hama dan penyakit serta panen dan pengangkutan hasil panen. Penyerapan tenaga kerja terbanyak adalah pada kegiatan panen dan pengangkutan hasil panen dengan frekuansi panen antara 18 dan 24 kali pertahun.

Curahan tenaga kerja yang diberdayakan oleh petani dalam usahatani kelapa sawit rakyat di Kabupaten Solok Selatan khusunya Kecamatan Sangir Balai Janggo dapat diuraikan sebagai berikut:

Tabel 1. Alokasi Tenaga Kerja Menurut Jenis Pekerjaan Pada Kebun Rakyat Komoditi Kelapa Sawit di Kab. Solok Selatan

\begin{tabular}{llc}
\hline No. & \multicolumn{1}{c}{ Jenis pekerjaan } & Jumlah Tenaga kerja(HOK/ha) \\
\hline 1. & Pembersihan lahan & 23 \\
2. & Penanaman & 18 \\
3. & Pemagaran & 18 \\
4. & Pemupukan & 1.5 \\
5. & Panen & 24 \\
\hline & Total & 84.5 \\
\hline
\end{tabular}

Sumber: Data Primer Diolah, 2016.

Curahan tenaga kerja dalam pengelolaan perkebunan kelapa sawit rakyat di Kab. Solok Selatan rata-rata berjumlah $84.5 \mathrm{HOK} /$ ha atau sama dengan 772 jam kerja/ha. Dengan catatan bahwa 1 HOK sama dengan 8 jam kerja. Angka ini lebih kecil dibandingkan dengan curahan tenaga kerja pada perkebunan kelapa sawit rakyat di Kab. Muko-muko sebesar 85,79 HOK/tahun (Alfayanti dan Zul, 2013). Hal ini mengindikasikan bahwa pengelolaan perkebunan kelapa sawit di Kab. Solok Selatan belum optimum. Menurut Mara dan Yanuar, (2012) semakin besar penyerapan tenaga kerja maka semakin intensif pengelolaan kebun kelapa sawit.

\section{Pendapatan Tenaga Kerja}

Pendapatan tenaga kerja perkebunan rakayat komoditi kelapa sawit berbeda-beda berdasarkan tahapan pekerjaannya dan tingkat kesulitan pekerjaan tersebut. Pendapatan non usahatani termasuk kegiatan non pertanian, dapat dihitung dengan mengalikan antara jumlah jam kerja yang dicurahkan untuk suatu jenis pekerjaan dengan upah per jam kerja.

\section{Pendapatan non usahatani $=$ jam kerja $x$ upah per jam kerja}

Analisis pendapatan ini hanya digunakan untuk menghitung pendapatan yang merupakan hasil kerja (memiliki curahan jam kerja). Pendapatan yang 
tidak memiliki jam kerja seperti sewa dan kiriman dimasukkan juga kedalam komponen pendapatan rumahtangga, tetapi tidak perlu dilakukan perhitungan (Putri, 2008). Pendapatan rata-rata tenaga kerja pada perkebunan rakyat komoditi kelapa sawit di Kab. Solok Selatan, Kec. Sangir Balai Janggo dapat dilihat pada tabel berikut:

Tabel 2. Pendapatan Tenaga Kerja Kebun Rakyat Komoditi Kelapa Sawit Di Kab. Solok Selatan

\begin{tabular}{|c|c|c|c|c|c|}
\hline \multirow{2}{*}{$\begin{array}{c}\text { Jenis } \\
\text { Pekerjaan }\end{array}$} & \multicolumn{2}{|c|}{ Lahan } & \multirow[t]{2}{*}{ Uraian } & \multicolumn{2}{|c|}{$\begin{array}{l}\text { Pendapatan } \\
\text { (Rp./Ha/th) }\end{array}$} \\
\hline & Datar & Curam & & Datar & Curam \\
\hline $\begin{array}{l}\text { Pembersihan } \\
\text { lahan }\end{array}$ & $50.000 / \mathrm{hr}$ & $70.000 / \mathrm{hr}$ & $\begin{array}{c}23 \\
\mathrm{HOK} / \mathrm{ha} / \mathrm{th}\end{array}$ & $\begin{array}{c}1,250,0 \\
00\end{array}$ & $1,750,000$ \\
\hline Penanaman & $12.000 / \mathrm{btg}$ & $\begin{array}{r}15.000- \\
20.000 / \text { btg }\end{array}$ & $123 \mathrm{btg} / \mathrm{ha}$ & $\begin{array}{c}1,476,0 \\
00\end{array}$ & $\begin{array}{l}1,845,000- \\
2,460,000\end{array}$ \\
\hline Pemagaran & $50.000 / \mathrm{btg}$ & $70.000 / \mathrm{btg}$ & $123 \mathrm{btg} / \mathrm{ha}$ & $\begin{array}{l}6,150,0 \\
00\end{array}$ & $7,380,000$ \\
\hline Pemupukan & $50.000 / \mathrm{HOK}$ & $60.000 / \mathrm{HOK}$ & $\begin{array}{c}1.5 \\
\mathrm{HOK} / \mathrm{ha} / \mathrm{th}\end{array}$ & 75,000 & 90,000 \\
\hline Panen & $150.000 /$ ton & $200.000 /$ ton & $\begin{array}{l}2.16 \text { ton/ha } \\
\text { (24 kali } \\
\text { panen/th) }\end{array}$ & $\begin{array}{c}7,776,0 \\
00\end{array}$ & $10,368,000$ \\
\hline $\begin{array}{r}\text { Total Pendap } \\
\text { Lahan Da } \\
\text { Lahan Cu }\end{array}$ & $\tan$ & & & 1.433 .000 & $\begin{array}{r}16.727 .000 \\
-22.048 .000\end{array}$ \\
\hline $\begin{array}{r}\text { Pendapatan } \mathrm{t} \\
\text { Lahan Da } \\
\text { Lahan Cu }\end{array}$ & $\begin{array}{l}\text { naga kerja per } \\
\text { am }\end{array}$ & bulan (Rp.) & 1.786 & $6.083,33-$ & $\begin{array}{l}1.393 .916,67 \\
1.837 .333,33\end{array}$ \\
\hline $\begin{array}{r}\text { Pendapatan } \mathrm{t} \\
\text { Lahan Da } \\
\text { Lahan Cu }\end{array}$ & $\begin{array}{l}\text { naga kerja per } \\
\text { ir } \\
\text { am }\end{array}$ & HOK (Rp.) & & 53.644 .97 & $\begin{array}{r}197.952,66 \\
-260.923,08\end{array}$ \\
\hline $\begin{array}{r}\text { Pendapatan } \mathrm{t} \\
\text { Lahan Da } \\
\text { Lahan Cu }\end{array}$ & $\begin{array}{l}\text { naga kerja per } \\
\text { or } \\
\text { am }\end{array}$ & jam (Rp.) & & $31.705,62$ & $\begin{array}{r}24.744,08 \\
-32.615,38\end{array}$ \\
\hline
\end{tabular}

Sumber: Data Primer Diolah, 2016.

Berdasarkan Tabel 2 di atas dapat dilihat bahwa ada perbedaan pendapatan yang diterima oleh tenaga kerja kebun kelapa sawit rakyat dengan kontur lahan yang datar dan lahan yang relatif bergelombang atau curam. Untuk lahan yang relatif datar, pendapatan petani untuk setiap pekerjaan relatif lebih kecil dibandingkan dengan lahan yang bergelombang atau relatif curam. Namun keselamatan kerja perlu menjadi pertimbangan bagi tenaga kerja, karena lahan yang relatif curam mempunyai resiko yang lebih tinggi dibandingkan dengan lahan yang datar. Rata-rata pendapatan tenaga kerja per bulan sebesar

30 | Yulistriani dan Mahdi; Profil, Alokasi, dan Pendapatan Tenaga Kerja ... 
Rp. 1,393,916.67 (lahan datar) dan Rp. 1,786,083.33 s.d Rp. 1,837,333,33 (lahan curam). Namun tidak semua jenis pekerjaan tersedia secara rutin, tergantung dari keputusan pemilik lahan dalam pengelolaan kebun kelapa sawit yang dimiliki.

Berbeda dengan tenaga kerja di perusahaan perkebunan kelapa sawit yang mempunyai upah dan standar yang tetap. Pendapatan diatas diperoleh jika kita asumsikan bahwa setiap jenis pekerjaan tersedia setiap saat dan tenaga kerja menggunakan waktunya untuk aktif bekerja selama 8 jam per hari di perkebunan rakyat. Perlu dilakukan penelitian lanjutan apakah dengan besaran pendapatan tersebut tenaga kerja sudah dapat memenuhi kebutuhan hidup keluarganya dan telah mencapai taraf kesejahteraan.

\section{SIMPULAN DAN SARAN}

\section{Simpulan}

Perkebunan kelapa sawit rakyat mempunyai spesifikasi tersendiri dalam penggunaan tenaga kerja disetiap tahapan pengelolaan lahan kelapa sawit. Dari penelitian yang dilakukan pada kebun rakyat komoditi kelapa sawit di Kab. Solok Selatan ditemukan bahwa $\pm 75 \%$ tenaga kerja yang bekerja pada perkebunan rakyat komoditi kelapa sawit adalah tenaga kerja tingkat pendidikan SD ke bawah. Curahan tenaga kerja dalam pengelolaan perkebunan kelapa sawit rakyat di Kab. Solok Selatan rata-rata berjumlah $84.5 \mathrm{HOK} / \mathrm{ha} /$ th atau sama dengan $772 \mathrm{jam}$ kerja/ha. Rata-rata pendapatan tenaga kerja per bulan sebesar Rp. 1,393,916.67 (lahan datar) dan Rp. 1,786,083.33 s.d Rp. 1,837,333,33 (lahan curam).

\section{Saran}

Keberhasilan pengelolaan perkebunan kelapa sawit sangat ditentukan oleh kualitas tenagakerjanya. Oleh karena itu tenaga kerja perlu mendapat perhatian khusus sehingga dapat bekerja secara optimum dan memberikan hasil yang optimum juga. Keselamatan kerja perlu menjadi perhatian bersama setiap stakeholder terkait, baik tenaga kerja itu sendiri, pemilik lahan sebagai pengguna tenaga kerja, dan pemerintah sebagai pembuat kebijakan. Tenaga kerja kebun rakyat perlu juga mendapatkan jaminan sosial tenaga kerja seperti yang didapatkan oleh tenaga kerja pada perkebunan besar swasta dan BUMN. Dalam penentuan upah juga harus proporsional sesuai dengan tingkat kesulitan dan perlu juga mempertimbangkan tingkat kesejahteraan tenaga kerja dan keluarganya. 


\section{DAFTAR PUSTAKA}

Afifuddin, S., Kusuma, SI. 2007. Analisis Struktur Pasar CPO: Pengaruhnya terhadap pengembangan ekonomi wilayah Sumater Utara. Jurnal Perencanaan dan Pengembangan Wilayah. Vol. 2 No. 3. April 2007. Hal $124-136$.

Alfayanti dan Zul Efendi. 2012. Analisis Faktor-faktor yang Mempengaruhi Produksi Kelapa Sawit Rakyat di Kab. Mukomuko. Jurnal Agrisep Vol.12 No.1 Maret 2013. Hal. 1-10.

Badan Pusat Statistik. 2015. Statistik Solok Selatan 2015. Solok Selatan. 2013. Sumbar Dalam Angka 2013. Padang.

Direktorat Jenderal Perkebunan. 2011. Rencana Strategi Direktorat Jederal Perkebunan 2010-2014.Jakarta.

Lisa, Ridvia, Maschandra dan Rusman Iskandar. 2010. Analisis Data Kualitatif Model Miles dan Huberman (sebuah rangkuman dari buku Analisis Data Qualitatif, Mathew B. Miles dan A. Michael Huberman) Terjemahan Tjetjep Rohindi Rodidi, UI-Press 1992. Program Magister Pendidikan Kejuruan Fakultas Teknik Universitas Negeri Padang. Hal 11.

Mara, Armen dan Yanuar Fitri. 2012. Dampak Perkebunan Kelapa Sawit

Rakyat Terhadap Pendapatan Wilayah Desa di provinsi Jambi. Jurnal Agrisep Vol.12 No.1 Maret 2013. Hal.109-121.

Nazir. 2005. Metode Penelitian. Ghalia Indonesia. Jakarta

Putri, Risti Diana. 2008. Analisis Pendapatan dan Curahan Kerja Rumah Tangga

Petani Wortel di Desa Sukatani Kecamatan Pacet Kabupaten Cianjur.

Institut Pertanian Bogor. Bogor.

Suryana et al. 1982. Faktor Agroekonomi dan Sosial yang Mempengaruhi

Kualitas Usahatani. Forum Penelitian Agroekonomi I (1): 1-16.

Syahza, Almasdi. 2011. Percepatan Ekonomi Pedesaan Melalui Pembangunan Perkebunan Kelapa Sawit. Jurnal Ekonomi Pembangunan Vol.12 hlm.297-310.

Taryono. 2012. Analisis Belanja Daerah Kemiskinan dan Kesejahteraan Masyarakat antara Kabupaten/Kota Penghasil Migas dan Bukan Penghasil Migas di Provinsi Riau. Jurnal Sosial Ekonomi Pembangunan. Tahun III No. 7. Nov 2012. Hal 52 - 70.

32 | Yulistriani dan Mahdi; Profil, Alokasi, dan Pendapatan Tenaga Kerja ... 